\title{
Investigation and Project Analysis of College Student's Entrepreneurial Wish in the Pattern of Limited Partnership
}

\author{
Shi-hua $\mathrm{LI}^{1,3, \mathrm{a}}$, Zhi-yuan $\mathrm{Hu}^{2, \mathrm{~b}}$ and Zhang Wei, \\ ${ }^{1}$ School of management and engineering, Nanjing University, Nanjing 210093, China \\ ${ }^{2}$ School of Marxism, Hohai University, Nanjing 210098, China \\ ${ }^{3}$ Postdoctoral Workstation, Govtor Capital, Nanjing 210009 China \\ alishihua88@163.com, 'bubin0072@126.com, 'lishihua88@sina.com
}

Keywords: College student; Limited Partnership; Entrepreneurial Wish; Employment; Start-ups

\begin{abstract}
According to the problem that the intelligence is not high of the soccer robot, using the mechanical theory as a guide, making some mechanical analyses and calculations on the pressure and transmutation states of chip kick mechanics, and conducting optimal design too, then making the structure of chip kick mechanics more and more rationalization. Experiments show that the new soccer robot controller features a quick response and high servo rigidity, and provide a kind of method for improving and perfecting the soccer robot control system, at the same time, filling the needs of producing.
\end{abstract}

\section{Introduction}

Entrepreneurship is a process or an activity to create and establish a business [1].Entrepreneurship is a way of thinking, reasoning and behavior, and this way of behavior is driven by opportunities, methods and equilibrium with the leadership[2]. Since enlarging enrollment of high education in china in 1999, the graduates are increasing year after year, pressure on employment of college students are growing. Diversified employment channels become an inevitable trend of college students; meanwhile business Partnership has been also becoming a way to ease the employment pressure. In this context, it is very much necessary to study the pattern of college students' business partnership, especially limited partnership, in such a way we can not only understand the status of entrepreneurial wish in the pattern of limited partnership, but also find out rational way to alleviate the current problems of student's employment pressure. It is not a simple linear relationship between entrepreneurship and employment, but new venture will bring a direct impact on employment in the short term in the initial periods [3]. Finally, solve the problems existing in college students' entrepreneurial wish-category of motivations which constitutes the basis of the behavior of human beings[4]. This subject adopts targeted interview survey, and the approach of data collection combines self-administered questionnaires with visit method. Taking Huangshan University (a typical China's Midwest University) as a survey site for an example, a representative reaction of students' entrepreneurial wish in partnership will be presented. Because of the limitation of conditions, the sample elements use a random sampling method, the total sample of 100 questionnaires.

\section{Results of investigation}

The survey collected a total of 100 questionnaires, conducted a survey of 100 college students in Huangshan University, freshman 30, sophomore 30, junior 40. There are 40 boys and 60 girls respectively. For a large number of senior students left school for practice or finding jobs, so they are not the objects in our survey. The survey shows that: the entrepreneurial willingness of boys is more Intensive than girls', 85\% and 57\% respectively; high grade than low-grade student, 76\% and $54 \%$ respectively; Industrial choice of future entrepreneurial wish in limited partnership includes the food service industry $43 \%$, computer $8 \%$, advertising $11 \%$, finance $16 \%$, garment industry $9 \%$, other $13 \%$. 


\subsection{Understanding of starting a business in partnership}

The survey shows that about $84 \%$ of the students believe that the starting-business is to create a career, which is consistent with the fact, and indicates that my college students have a macro understanding, open thinking conducive to the development of the cause? However, science and engineering students are more inclined to develop cutting-edge sci-and-tech projects. About $73 \%$ of the students have idea of starting a business, $19 \%$ of the students do not have, and $8 \%$ do not care about. However, although the majority of students want to start a business in partnership, but only $35 \%$ of the students began to prepare, $65 \%$ of the students did not prepare. The survey also found that, in the selection of entrepreneurial mode, $64 \%$ of the students tend to choose the pattern of partnership as Figure 1 shows.

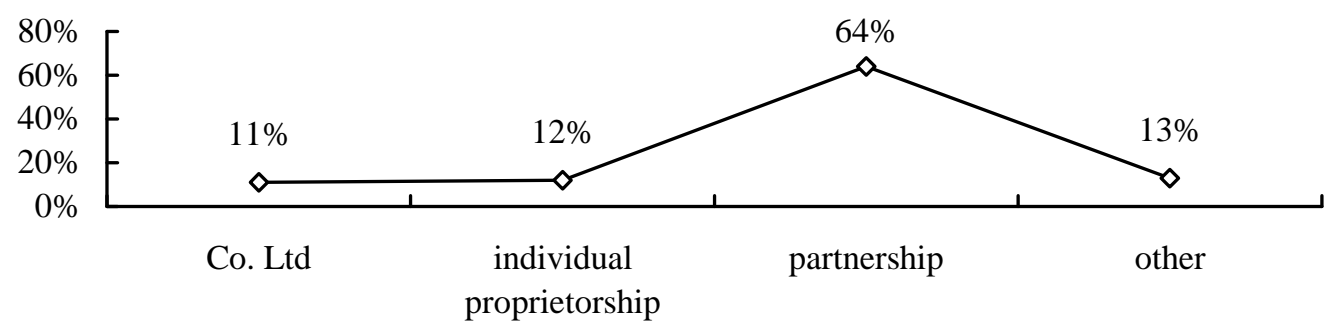

Figure 1 The choice of different entrepreneurial model

\subsection{The preparatory work of starting a business in partnership}

Singh (2001) believes that entrepreneurship is the process to create a new enterprise [3]. This course needs an adequate preparation. The college students who have done preparation for starting a business in partnership accounts for about 35\%, in which about $14 \%$ of the students advocates practicing into an enterprise, $18 \%$ tends to take part in entrepreneurship training, $7 \%$ participate in the Business Plan Competition, 53\% advocates learning business knowledge from entrepreneurial books, $38 \%$ are ready to go to the internship, $4 \%$ tends to seek help entrepreneurial entrepreneurs. On how to obtain the knowledge and skills of entrepreneurship, $13 \%$ of the students hope to learn from teachers' lecture, and $47 \%$ want to participate in activities and training, $36 \%$ of students want to get through their own hands, about $4 \%$ of the students hope to obtain the knowledge and skills of the business partnership by other means (See Fig. 2).

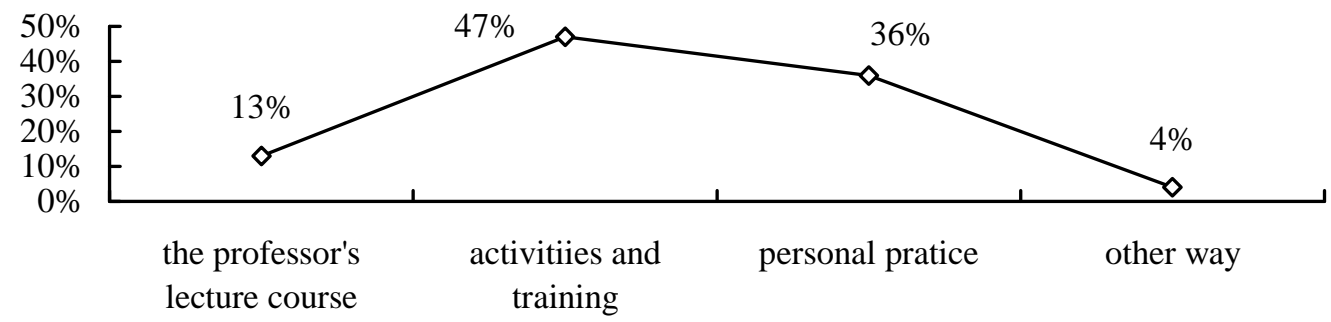

Figure 2 The obtaining way of entrepreneurial knowledge and skills

After making forecast of the prospects of college students' business in the pattern of partnership, only $8 \%$ express their confidences, $13 \%$ on the entrepreneurial prospects feel confused, $28 \%$ of the students have a certain pressure, $47 \%$ of the students think that starting-business in partnership like a gambling, and $19 \%$ of students choose other ways.

\subsection{The preparatory work of starting a business in partnership}

For undergraduates, there are a lot of obstacles during the course of starting business in the pattern of partnership. This investigation mainly involves such indexes as lack of money, inexperience, further studies, family's opposition, larger pressures and others. The survey showed that: $47 \%$ of the students believe that the biggest entrepreneurial obstacle is the lack of funds, and have no better direction; $23 \%$ of students believe they lack experience and social relations; $13 \%$ of students consider that they need further studies, $6 \%$ are getting the objections of the family, $17 \%$ think that, when facing ventures, the heart affordability is not enough, as Fig.3 shows. 


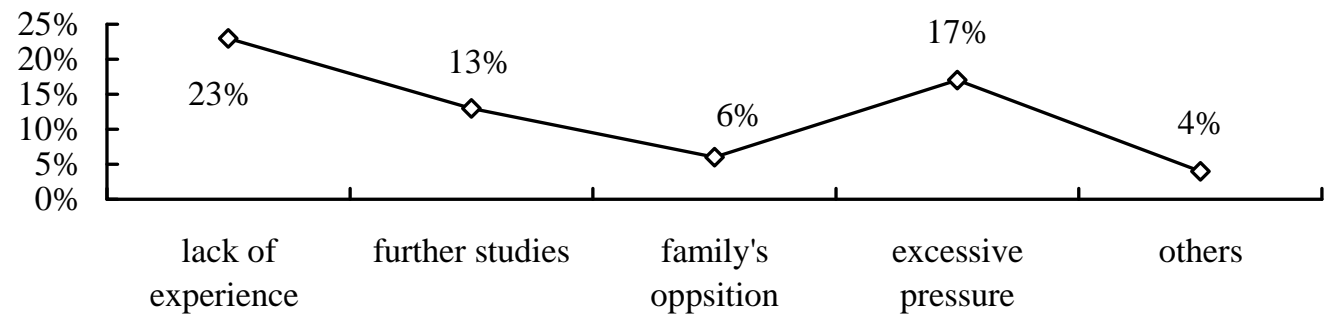

Figure 3 The obtaining way of entrepreneurial knowledge and skills

\subsection{The choice of a partner}

With reference to starting venture, it is essential to choose a partner, which sometimes also determines the success and failure of the investment even if you have a good project. The survey shows that, in the choice of partners, $4 \%$ of the students hope to choose peers (people of her own age), $42 \%$ of the students want to start a business with people with the same experience, $16 \%$ want to cooperate with partners with highly education, $31 \%$ want to work with people with a certain economic base, $7 \%$ of the students want to start business with friends and relatives (in Figure 4).

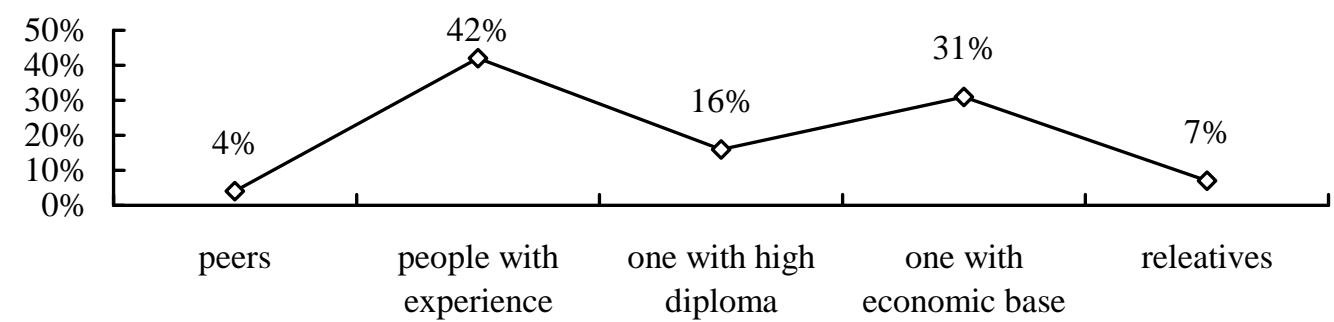

Figure 4 The college students' conditions of the choice of a partner

\section{Existing problems in college student's entrepreneurial wish in partnership}

\subsection{The lack of enough preparatory work}

College students have entrepreneurial intention, but the indexes of entrepreneurial practice are too low. There are still a great number of questions on starting an undertaking: the preparatory work of venture is not enough; there is no clear entrepreneurial direction. The partnership entrepreneurship is a more complex entrepreneurial model; especially early it is difficult for inexperienced college students in start-up stage. There is no enough money and experience, even if the start-up is opened, the start-up will be closed for a not long time.

\subsection{The lack of rationality in the choice of a partner}

Singh (2001) believes that entrepreneurship is the process to create a new enterprise [5]. In the legal sense the selection of partner of a partnership venture tend to choose investors with mutual trust together, but for this particular group of college students, the element of capital and experience may be more important. The college students who have not yet leave the campus, have no experience, no money, no interpersonal relationships, so entrepreneurship is difficult, especially more difficult after the venture. For this reason, there is contradiction in selecting partner.

Additionally, this investigation shows that college student in Hungshan University have entrepreneurial awareness, but their mental capacity are too strong enough to endure failure of entrepreneurship.

\section{Conclusion and strategic recommendations of starting undertaking in partnership}

Entrepreneurship is a systematic project; it requires entrepreneurs to accumulate a series of certain knowledge in such aspects as corporate positioning, strategic planning, property relations, marketing, production organization, team building, financial system, such as accumulation. Believe that a lot of people, on behalf of certain entrepreneurial success concept with a good idea and creative entrepreneurial preparation of the problems you might encounter inadequate preparation or 
simply do not think about countermeasures designed exit mechanism. It is not enough to only have entrepreneurial wish, and it is necessary for college students to make full preparation and design a much better exit mechanism. As per this investigation and employment problem of college students in China, suggestions are as follows:

\subsection{Enhangce policy support}

For college students having entrepreneurial wishes, the majority of students must have a good business philosophy; relevant departments of the government should create a good entrepreneurial environment, and enact certain entrepreneurship policy to educate and support undergraduates' entrepreneurial intention. College students start their own undertaking so as to not solve their own career development but also bring more employment opportunity, which is essential for the promotion of economic and social development and maintaining social stability.

The government and university create a good business environment. For example, in the respect of building college students' business incubator, effective leadership and coordination mechanism should be established in order to solve the problem of "underemployment" on the basis of the implementation of "Guidance Planning of College Student's Entrepreneurship". Colleges and universities should establish specialized institutions of entrepreneurship education and training faculty, and identified entrepreneurship education as elective courses. Additionally, Universities can make full use of campus resources, and promote the launching of the Campus' Business Plan Competition.

\subsection{Establish clear process of starting an undertaking}

Firstly, there lives a clear positioning: that is who I am, what I can do, what I have to do; Secondly, according the requirement for a standard Business Plan, a business plan for this entrepreneurial project should be written, and the item concerns "people, money and content", "production, supply, and marketing". Thirdly, you can invite people-who are more familiar with the industry-to find prick on your plan and give the feasibility analysis. Fourthly, management teams should be built, partners should be selected, and at the same time the principles of cooperation should be determined. Finally, an operating plan and implementation plan should be formulated.

\subsection{Act from the reality}

As a partnership venture for college students Huangshan University as a typical mid-west university, those college students who would like to venture must combine their own theory learned from campus with practice in the society. That is to do everything from the reality. Starting undertaking isn't just a matter of entrepreneurial wishes. It is with actual action that the success possibility of starting an undertaking in limited partnership would be increased.

\section{Acknowledgements}

This work was financially supported by: Govtor Capital (JSGOVTOR2012); "Doctor clustering scheme of enterprises in Jiangsu Province-the category of Enterprise postdoctoral"; and the scientific research innovation project in Jiangsu province (CXZZ12-0222).

\section{References}

[1] Yan-fu Jiang, Global Entrepreneurship Monitor 2002 Report, Beijing: Tsinghua University Press, 2003.

[2] Man-hong Liu, Venture capital: innovation and financial, Beijing,China Renmin University Press, 2005.

[3] Fritsch M. Effects of new business formation on regional development over time [J]. Regional Studies, 2004, 38: 961-975.

[4] Weiner, B. An attributional theory of achievement motivation and emotion. Psychological Review, 1985, 548-573.

[5] Singh, R. 2001. A comment on developing the field of entrepreneurship through the study of opportunity recognition and exploitation. Academy of Management Review, 26(1): 10-12. 